\title{
Identification of Pns6, a putative movement protein of RRSV, as a silencing suppressor
}

Jianguo $\mathrm{Wu}^{1,2+}$, Zhenguo $\mathrm{Du}^{1 \dagger}$, Chunzheng Wang ${ }^{2}$, Lijun Cai ${ }^{1}$, Meiqun $\mathrm{Hu}^{1}$, Qiying Lin, Zujian $\mathrm{Wu}^{1 *}$, Yi Li ${ }^{2^{*}}$, Lianhui Xie ${ }^{1 *}$

\begin{abstract}
RNA silencing is a potent antiviral response in plants. As a counterdefense, most plant and some animal viruses encode RNA silencing suppressors. In this study, we showed that Pns6, a putative movement protein of Rice ragged stunt virus (RRSV), exhibited silencing suppressor activity in coinfiltration assays with the reporter green fluorescent protein (GFP) in transgenic Nicotiana benthamiana line 16c. Pns6 of RRSV suppressed local silencing induced by sense RNA but had no effect on that induced by dsRNA. Deletion of a region involved in RNA binding abolished the silencing suppressor activity of Pns6. Further, expression of Pns6 enhanced Potato virus $\times$ pathogenicity in $N$. benthamiana. Collectively, these results suggested that RRSV Pns6 functions as a virus suppressor of RNA silencing that targets an upstream step of the dsRNA formation in the RNA silencing pathway. This is the first silencing suppressor to be identified from the genus Oryzavirus.
\end{abstract}

Plant infecting reoviruses are grouped into three genera, namely Phytoreovirus, Fijivirus and Oryzavirus [1]. RRSV belongs to the genus Oryzavirus. It infects plants in the family Graminae and is transmitted in a persistent manner by brown plant hoppers. The disease caused by this virus was first discovered in 1976-1977 in Indonesia and Philippines. Then the disease became prevalent in most rice-growing countries in south-eastern and far-eastern Asia, causing great yield losses to rice production [2]. RRSV virion has an icosahedral particle which consists of a polyhedral core surrounded by flat spikes about $20 \mathrm{~nm}$ wide and $10 \mathrm{~nm}$ high [3]. The RRSV genome comprises 10 double stranded RNAs with molecular weights ranging from 1.2 to $3.9 \mathrm{~kb}$ [4]. The complete nucleotide sequences of all genomic segments, denoted as S1-S10, have been determined. It is now known that proteins encoded by S6, S7 and S10, with Mrs of about $71 \mathrm{kD}, 68 \mathrm{KD}$ and $32 \mathrm{KD}$, respectively, are non-structural proteins, whereas proteins specified by

\footnotetext{
* Correspondence: wuzujian@126.com; liyi@pku.edu.cn; xielh@fjau.edu.cn + Contributed equally

'Institute of Plant Virology, Fujian Agriculture and Forestry University , Key Laboratory of Plant Virology of Fujian Province, Fuzhou, Fujian, China ${ }^{2}$ Peking-Yale Joint Center for Plant Molecular Genetics and

Agrobiotechnology, The National Laboratory of Protein Engineering and Plant Genetic Engineering, College of Life Sciences, Peking University, Beijing China

Full list of author information is available at the end of the article
}

other RNA segments have been shown to be present in or are supposed to take part in the assembly of RRSV virions [5-13]. However, our knowledge on the roles played by RRSV encoded proteins in virus-host interaction remains poor.

RNA silencing is now a general term that refers to a set of related processes in which small RNAs ranging from 21 to $30 \mathrm{nt}$ in length are used to direct sequence specific modulation of gene expression [14]. In plants as well as in some animals, one of the firmly established roles of RNA silencing is antiviral defense $[15,16]$. The antiviral RNA silencing begins with the cleavage of viral dsRNAs by members of the RNase III family enzymes called Dicer or Dicer-like (DCL) in plants, which results in the production of viral small interfering RNAs (VsiRNAs). These vsiRNAs are incorporated into an effector complex named RNA induced silencing complex (RISC) and then direct the complex to destroy viral RNAs $[15,16]$. VsiRNAs also provide sequence specificity for cellular RDRs to copy viral RNAs into dsRNAs, which can be a secondary source for vsiRNAs production $[17,18]$. As a counterdefence, many viruses have evolved to encode one or multiple proteins to suppress RNA silencing $[15,19]$. The molecular mechanisms by which these virus encoded silencing suppressors (VSRs) interfere with the RNA silencing machinery are poorly understood at present. VSRs from diverse viruses posses 
RNA binding activities. This led to the proposition that RNA might be a common target of VSRs. [20,21]. Some VSRs such as p19, HC-Pro and p21 efficiently form complexes with 21-nt ds-sRNA but fail to bind long dsRNA. These VSRs were believed to prevent the formation of functional RISCs by sequestering vsiRNAs. Some VSRs including CP of Turnip crinkle virus (TCV) bind dsRNAs without size selection. These VSRs may function to protect viral dsRNAs from being cleaved by plant DCLs $[20,21]$. Many recent studies demonstrated that VSRs could also target protein components of RNA silencing [for a review see 22]. Protein components of the RNA silencing that have been found to be targets of VSRs include DRB4, which is an auxiliary factor of the antiviral sensor DCL4; AGO1, which forms the core of RISC; and SGS3 which is a cofactor of RDR6 functioning in the amplification step of RNA silencing [22]. Regardless of all these possibilities, it is believed that VSRs play important roles in promoting viral replication as well as in viral pathogenesis [23].

The VSRs for members of the other two genera of Phytopathogenic reoviruses have been identified [24-26]. However, no VSR for Oryzavirus has been reported, nor can it be predicted because of the low level of sequence similarity between proteins of reoviruses across genera. Given the importance of VSRs in virus-host interaction, we conducted experiments to identify the VSR of RRSV.

It was reasonable to presume that the silencing suppressor function of RRSV was encoded by a nonstructural protein. Therefore, the ORFs for the three non-structural proteins, pns6, pns7 and pns10, were individually cloned into the binary vector pPZP212(See Additional file 1 and 2 for Materials and Methods). The resultant plasmids were named 35S-S6, 35S-S7, and $35 \mathrm{~S}-\mathrm{S} 10$ respectively (Figure 1 ). Transformed agrobacterial strain carrying each of these constructs was mixed with a strain that carried 35S-GFP with a ratio of 3:1 and infiltrated into leaves from Nicotiana benthamiana line $16 \mathrm{c}$ as described previously [27]. Then the GFP fluorescence was monitored using a handheld long wavelength UV light source. Agrobacteria harboring only the GFP gene or the $2 \mathrm{~b}$ gene of Tomato aspermy cucumovirus (TAV) were used as negative and positive controls, respectively [28].

All infiltrated leaf patches showed bright green fluorescence at 2 days post infiltration (dpi.) (Data not shown). In leaf patches infiltrated with 35S-GFP plus 35S-S6 or plus $35 \mathrm{~S}-2 \mathrm{~b}$, the fluorescence intensity remained strong until 7dpi (Figure 2A, C). However, in leaf patches expressing GFP or GFP plus either S7 or S10, the fluorescence intensity began to decline at $3 \mathrm{dpi}$ and became hardly detectable at 7dpi (Figure 2D,E). Similar patterns of fluorescence decline were observed in leaf patches infiltrated with $35 \mathrm{~S}$-GFP plus $35 \mathrm{~S}-\Delta \mathrm{S} 6$ (Figure $2 \mathrm{~B}$ ). The $35 \mathrm{~S}-\Delta \mathrm{S} 6$ carried the same $\mathrm{S} 6$ gene sequence as $35 \mathrm{~S}-\mathrm{S} 6$, but was supposed to be unable to express a functional Pns6 protein because of the deletion of the nucleotide A from the translation start codon AUG (Figure 1).

To test whether silencing suppression was responsible for the above observations, Northern blot analyses were conducted to detect steady-state levels of GFP mRNA and GFP-specific siRNAs. As shown in Figure 2G, the accumulation levels of GFP mRNA were much higher in tissues expressing 35SGFP plus 35S-TAV2b or 35S-GFP plus 35S-S6 than in tissues expressing GFP alone or in combination with any other genes at $7 \mathrm{dpi}$. This indicated that expression of S6 resulted in the stabilization of GFP mRNA and consequently higher GFP fluorescence, as that of TAV2b. In all treatments, the accumulation levels of GFP mRNA were negatively correlated with those of GFP-specific siRNAs (Figure 2G). This confirmed that Pns6 is a silencing suppressor.

\section{PZP212-S6 PZP212-S7 S6 PZP212-S10 WIIA PZP212- $\triangle S 6$ PZP212- S6 $\triangle$ 201-273AA S6-noATG S6 $\triangle 201-273 A A$



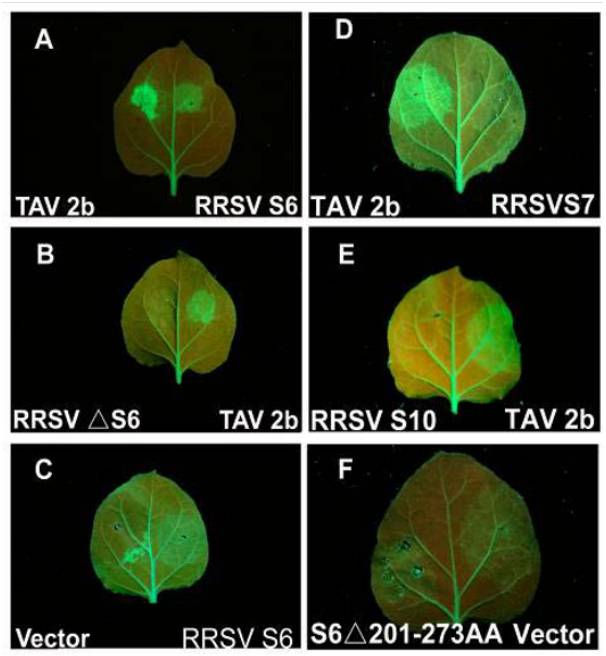

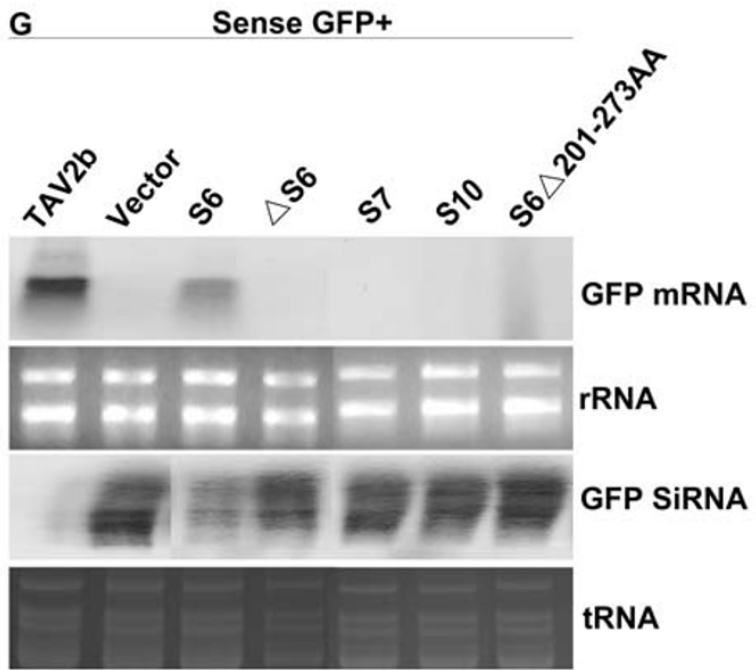

Figure 2 Suppression of local GFP silencing by RRSV Pns6. (A-F) N. benthamiana line 16c plants were coinfiltrated with Agrobacterium spp. (Agro.) mixtures carrying 35S-GFP and the individual constructs indicated in each image. GFP fluorescence was viewed under longwavelength UV light at 7 days postinfiltration (dpi). (G) Northern blot analysis of the steady-state levels of GFP mRNA and siRNA extracted from different infiltrated patches shown in panel A to F. 28 S rRNA and t RNA were used as loading controls for detection of GFP mRNA and GFP siRNA respectively.

As mentioned above, RNA silencing is a multi-step process [17]. To determine in which step Pns6 targets RNA silencing, we tested the effect of Pns6 on GFP dsRNA-triggered silencing. To do this, leaves of transgenic $N$. benthamiana plant line $16 \mathrm{c}$ were infiltrated with Agrobacterium tumefaciens harboring 35S-ssGFP (sense GFP RNA), 35S-dsGFP (IR-GFP), and a binary vector containing $S 6, \Delta S 6$, or TAV2b under the control of the $35 \mathrm{~S}$ promoter. As shown in Figure 3, leaf patches infiltrated with $35 \mathrm{~S}$-ssGFP plus $35 \mathrm{~S}$-dsGFP or with $35 \mathrm{~S}$ ssGFP plus 35S-dsGFP plus $35 \mathrm{~S}-\mathrm{S6}$ (or $35 \mathrm{~S}-\Delta \mathrm{S}$ ) lost GFP fluorescence at $7 \mathrm{dpi}$, indicating strong GFP RNA silencing. Consistently, the accumulation of GFP mRNA was hardly detectable in these leaf patches. This suggested that Pns6 could not suppress silencing induced by dsRNA. As expected, TAV2b suppressed GFP RNA silencing triggered by dsRNA, as indicated by the bright green fluorescence and high levels of accumulation of GFP mRNA in leaves infiltrated with 35S-ssGFP plus 35S-dsGFP plus 35S-TAV2b (Figure 3).

These data showed that pns6 of RRSV had silencing suppressor activities. It targeted an initial step of RNA silencing upstream of dsRNA production. This was consistent with a previous report which demonstrated that Pns6 of RRSV had nucleic acid binding activities and preferentially bound ssRNAs [12]. Nucleic acids binding is a common feature of many VSRs. It is possible that Pns6 binds ssRNAs and prevents them from being copied by cellular RDRs. In a primary attempt to exploit this possibility, we generated $\Delta$ S6201-273, in which the animo acids from 201 to 273 were deleted (Figure 1). This region of amino acids has been shown to be essential for RNA binding of RRSV pns6 [12]. Indeed, the S6 mutant lost silencing suppressor activity: when coexpressed with GFP in leaves of $N$. benthamiana line $16 \mathrm{c}$, it could not maintain strong GFP fluorescence in infiltrated leaf patches. The GFP mRNA accumulation level was very low at 7dpi., whereas that of GFP siRNAs was markedly high (Figure 2F).

Results from the above experiments indicated that RRSV Pns6 was a silencing suppressor but offered no clues with regards to whether this function would have biological implications for viral infection. The role of Pns6 in RRSV infection can not be tested directly because of the lack of an infectious clone for this virus. Therefore, we utilized pGR107, a PVX vector to express S6 in a heterologous virus. Seedlings of $N$. benthamiana plants (four-to six-leaf stage) were inoculated with PVX, PVX-S6 or PVX- $\Delta$ S6, respectively.

Variations in symptom severity were observed in individual infections. However, a general trend was that PVX-S6 elicited more severe symptoms than PVX or PVX- $\Delta$ S6 did. This was especially obvious after 9 dpi. At this time, only mild chlorotic spots could be observed on some leaves from $N$. benthamiana infected by PVX or PVX- $\Delta$ S6. However, most plants infected by PVX-S6 exhibited very severe symptoms, with some newly developed leaves being abnormal in shape (Figure 4A). The symptoms induced by PVX-S6 sustained throughout the life of the plants, whereas only a small proportion of 

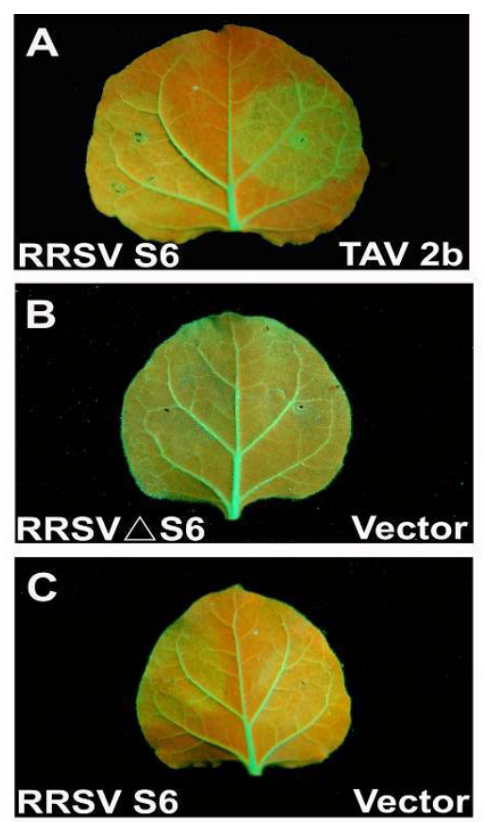

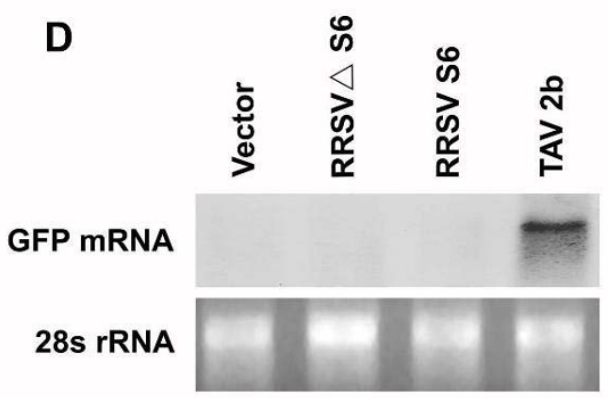

Figure 3 RRSV Pns6 can not inhibit local silencing induced by dsRNA (A-C) $\mathbf{N}$. benthamiana line $16 \mathrm{c}$ plants were coinfiltrated with Agrobacterium spp. (Agro.) mixtures carrying 35S-dsGFP and the individual constructs indicated in each image. GFP fluorescence was viewed under longwavelength UV light at 7 days postinfiltration (dpi). (D) Northern blot analysis of the steady-state levels of GFP mRNA extracted from different infiltrated patches shown in panel A to C. The bottom gel shows rRNA with ethidium bromide staining as a loading control.

plants infected by PVX or PVX- $\Delta$ S6 were symptomatic during later stages of observation. These results showed that RRSV S6 can accentuate symptoms when expressed by a heterologous virus. To correlate this function of RRSV S6 with silencing suppression, the accumulation levels of PVX in systemically infected N. benthamiana plants were detected. Northern blot analysis revealed that the concentration of PVX in plants infected by PVX-S6 was very high at $18 \mathrm{dpi}$. In contrast, the presence of PVX RNA was hardly detectable in newly
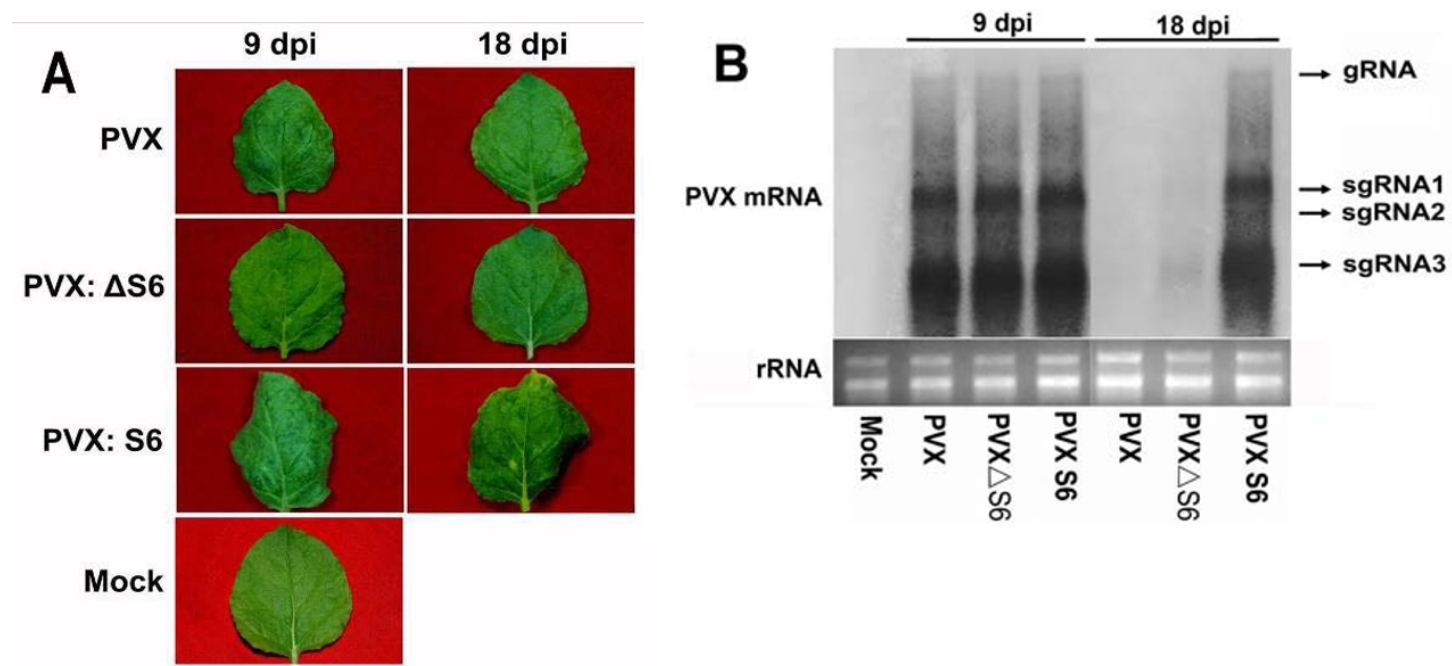

Figure 4 RRSV Pns6 enhances pathogenicity of chimeric PVX. (A) plants infected by PVX $\triangle S 6$ or PVXâ- ${ }^{3} S 6$ show mild disease symptoms as a few scattered chlorotic speckles, whereas leaves infected with PVX-S6 show more severe symptoms. (B) RNA gel blot analysis of accumulation of PVX genomic (gRNA) and subgenomic mRNAs (sgRNA1 to sgRNA3) at 9 and 18 dpi. The bottom gel shows rRNA with ethidium bromide staining as a loading control. 
developed leaves from plants infected by PVX or PVX$\triangle \mathrm{S} 6$ at this time (Figure $4 \mathrm{~B}$ ). This indicated that RRSV S6 markedly enhanced the replication of PVX, presumably through suppression of RNA silencing. However, it was interesting to note that no differences in the accumulation of PVX RNAs were detected between plants infected by PVX-S6 and those infected by PVX or PVX$\triangle \mathrm{S} 6$ at $9 \mathrm{dpi}$ (Figure $4 \mathrm{~B}$ ). As plants infected by PVX-S6 showed more severe symptoms than those infected by PVX or PVX- $\triangle$ S6 at this time (Figure 4A), this implicated that Pns6 might have direct effects on the normal physiology of the infected plants independent of its ability to enhance viral multiplication.

Taken together, we identified pns6, which is composed of 592 amino acids with a molecular weight of about $65 \mathrm{kDa}$, as a silencing suppressor of RRSV. This was the first VSR to be identified from an oryzavirus. We showed that the RNA binding activities of Pns6 might be important for its silencing suppressor function. Similar studies on other VSRs of plant infecting reoviruses have yet to be done [24-26]. Interestingly, we have recently reported that pns6 might be a cell-to-cell movement protein of RRSV. Pns6 could complement the cell-to-cell movement of the movement-deficient TMV in N. tabacum Xanthi $n c$ and N. benthamiana plants. When transiently expressed in epidermal cells from N. benthamiana, the Pns6-eGFP fusion protein was present predominantly along the cell wall [29]. This was consistent with the notion that virus movement and RNA silencing are intimately related processes. Some well-known VSRs including p19, 2b, Hc-Pro had been implicated in virus long-range movement before the recognition of their silencing suppressor activities [30-33]. For Tobacco Etch Potyvirus HcPro protein, a correlation of silencing suppression and the ability to mediate long-distance virus movement has been demonstrated [34]. Through random mutagenesis of the P25 gene, Bayne et al. showed that suppression of silencing is necessary for cell-to-cell movement of PVX through plasmodesmata [35]. In addition, the movement-deficiency phenotype of a TCV CP deletion mutant could be complemented by a series of silencing suppressors in Trans [36]. Thus, our findings may serve as an example in which a protein encoded by a rice virus functions in both RNA silencing and viral movement.

\section{Additional material}

Additional file 1: Materials and Methods. Word DOC containing the Materials and Methods section.

Additional file 2: Table S1: Primers used in this study.

\section{Acknowledgements}

We thank Dr.Jason G. Powers for providing plasmid pPZP212 vecrot and Prof. David Baulcombe for providing $16 c$ seeds and PVX vectors. This work was supported by the Major Project of Chinese National Programs for Fundamental Research and Development (grant no.2010CB126203), the National Natural Science Foundation of China (grant no.30970135), the Fujian Province Education Department (grantno.JB08078), the National Science Foundation of China (30970135) and Specialized Research Fund for the ministry of agriculture (nyhyzx 07-051).

\section{Author details}

${ }^{1}$ Institute of Plant Virology, Fujian Agriculture and Forestry University, Key Laboratory of Plant Virology of Fujian Province, Fuzhou, Fujian, China. ${ }^{2}$ Peking-Yale Joint Center for Plant Molecular Genetics and

Agrobiotechnology, The National Laboratory of Protein Engineering and Plant Genetic Engineering, College of Life Sciences, Peking University, Beijing China.

\section{Authors' contributions}

JW and ZD performed the experiments, analyzed the data, and drafted the manuscript and contributed equally to this work. CW, LC, MH and QL assisted in the performance of the experiments. ZW, YL and LX designed the study, interpreted the data and critically revised the manuscript. All authors read and approved the final manuscript.

\section{Competing interests}

The authors declare that they have no competing interests.

Received: 16 March 2010 Accepted: 22 November 2010 Published: 22 November 2010

\section{References}

1. Mertens PPC, Attoui H, Duncan R, Dermody TS: Virus taxonomy. Eighth report of the International Committee on Taxonomy of Viruses. Reoviridae Elsevier Academic Press, San Diego, CA; 2005, 447-454.

2. Ling KC, Tiongco ER, Aguiero VM: Rice ragged stunt, a new virus disease. Plant Dis Rep 1978, 62:701-705.

3. Hagiwara K, Minobe Y, Nozu Y, Hibino H, Kimura I, Omura T: Component proteins and structures of rice ragged stunt virus. J Gen Virol 1986, 67:1711-1715.

4. Omura T, Minobe $Y$, Kimura I, Hibino H, Tsuchizaki T, Saito Y: Improved purification procedure and RNA segments of Rice ragged stunt virus. Ann Phytopathol Soc Jpn 1983, 49:670-675.

5. Miyazaki N, Uehara-lchiki T, Xing L, Bergman L, Higashiura A, Nakagawa A, Omura T, Cheng RH: Structural evolution of reoviridae revealed by oryzavirus in acquiring the second capsid shell. J Virol 2008, 82:11344-11355.

6. Upadhyaya NM, Ramm K, Gellatly JA, Li Z, Kositratana W, Waterhouse PM: Rice ragged stunt Oryzavirus genome segment S4 could encode an RNAdependent RNA polymerase and a second protein of unknown function. Arch Virol 1998, 143:1815-1822.

7. Li Z, Upadhyaya NM, Kositratana W, Gibbs AJ, Waterhouse PM: Genome segment 5 of rice ragged stunt virus encodes a virion protein. J Gen Virol 1996, 77:3155-3160.

8. Upadhyaya NM, Ramm K, Gellatly JA, Li Z, Kositratana W, Waterhouse PM: Rice ragged stunt oryzavirus genome segments $\mathrm{S} 7$ and $\mathrm{S} 10$ encode nonstructural proteins of $M(r)$ 68,025 (Pns7) and $M(r)$ 32,364 (Pns10). Arch Virol 1997, 142:1719-1726.

9. Upadhyaya NM, Zinkowsky E, Kositratana W, Waterhouse PM: The Mr 43K major capsid protein of rice ragged stunt Oryzavirus is a posttranslationally processed product of a $\mathrm{Mr} 67,348$ polypeptide encoded by genome segment 8 . Arch Virol 1996, 141:1689-1701.

10. Uyeda I, Suga H, Lee SY, Yan J, Hataya T, Kimura I, Shikata E: Rice ragged stunt Oryzavirus genome segment 9 encodes a 38,600 Mr structural protein. J Gen Virol 1995, 76:975-978.

11. Upadhyaya NM, Ramm K, Gellatly JA, Li Z, Kositratana W, Waterhouse PM: Rice ragged stunt Oryzavirus genome segment S4 could encode an RNAdependent RNA polymerase and a second protein of unknown function. Arch Virol 1998, 143:1815-1822. 
12. Hagiwara K, Rao S, Scott SW, Carner GR: Nucleotide sequences of segments 1, 3 and 4 of the genome of Bombyx mori cypovirus 1 encoding putative capsid. J Gen Virol 2002, 83:1477-1482.

13. Shao CG, LÜ HJ, Wu JH, Gong ZX: Nucleic acid binding activity of Pns6 encoded by genome segment 6 of rice ragged stunt oryzavirus. Acta Biochim Biophys Sin (Shanghai) 2004, 36:457-466.

14. Brodersen $\mathrm{P}$, Voinnet $\mathrm{O}$ : The diversity of RNA silencing pathways in plants. Trends Genet 2006, 22:268-280

15. Ding SW, Voinnet O: Antiviral immunity directed by small RNAs. Cell 2007, 130:413-26.

16. Ding SW: RNA-based antiviral immunity. Nat Rev Immuno 2010, 10:632-644.

17. Baulcombe D: RNA silencing in plants. Nature 2004, 431:356-363.

18. Voinnet $\mathrm{O}$ : Use, tolerance and avoidance of amplified RNA silencing by plants. Trends Plant Sci 2008, 13:317-328.

19. Li F, Ding SW: Virus counterdefense: diverse strategies for evading the RNA-silencing immunity. Annu Rev Microbiol 2006, 60:503-531.

20. Lakatos L, Csorba T, Pantaleo V, Chapman EJ, Carrington JC, Liu YP, Dolja W, Calvino LF, López-Moya JJ, Burgyán J: Small RNAbinding is a common strategy to suppress RNA silencing by several viral suppressors. EMBO J 2006, 25:2768-2780.

21. Merai Z, Kerenyi Z, Kertesz S, Magna M, Lakatos L, Silhavy D: Doublestranded RNA binding may be a general plant RNA viral strategy to suppress RNA silencing. J Virol 2006, 80:5747-56.

22. Wu QF, Wang XB, Ding SW: Viral suppressors of RNA-based viral immunity: host targets. Cell Host Microbe 2010, 8:12-15.

23. Di'az-Pendo'n JA, Ding SW: Direct and indirect roles of viral suppressors of RNA silencing in pathogenesis. Annu Rev Phytopathol 2008, 46:303-326.

24. Zhang LD, Wang ZH, Wang XB, Li DW, Han CG, Zhai YF, Yu JL: Two virusencoded RNA silencing suppressors, $\mathrm{P} 14$ of Beet necrotic yellow vein virus and S6 of Rice black streak dwarf virus. Chin Sci Bull 2005, 50:305-310.

25. Cao X, Zhou P, Zhang X, Zhu S, Zhong X, Xiao Q, Ding B, Li Y: Identification of an RNA silencing suppressor from a plant doublestranded RNA virus. J Virol 2005, 79:13018-13027.

26. Liu F, Zhao Q, Ruan X, He Y, Li H: Suppressor of RNA silencing encoded by Rice gall dwarf virus genome segment 11. Chinese Sci Bull 2008, 53:96-103.

27. Hamilton A, Voinnet O, Chappell L, Baulcombe D: Two classes of short interfering RNA in RNA silencing. EMBO J 2002, 21:4671-4679.

28. Li HW, Lucy AP, Guo HS, Li WX, Ji LH, Wong SM, Ding SW: Strong host resistance targeted against a viral suppressor of the plant gene silencing defence mechanism. EMBO J 1999, 18:2683-2691.

29. Wu ZJ, Wu JG, Adkins S, Xie LH, Li WM: Rice ragged stunt virus segment S6-encoded nonstructural protein Pns6 complements cell-tocellmovementof Tobacco mosaic virus-based chimeric virus. Virus Res 2010, 152:176-179

30. Scholthof HB, Scholthof KB, Kikkert M, Jackson AO: Tomato bushy stunt virus spread is regulated by two nested genes that function in cell-tocell movement and host-dependent systemic invasion. Virology 1995, 213:425-438.

31. Cronin S, Verchot J, Haldeman-Cahill R, Schaad MC, Carrington JC: Long distance movement factor: a transport function of the potyvirus helper component proteinase. Plant Cell 1995, 7:549-559.

32. Ding SW, Li WX, Symons RH: A novel naturally occurring hybrid gene encoded by a plant RNA virus facilitates long distance virus movement. EMBO J 1995, 14:5762-5772.

33. Klein PG, Klein RR, Rodriguez-Cerezo E, Hunt AG, Shaw JG: Mutational analysis of the tobacco vein mottling virus genome. Virology 1994, 204:759-769.

34. Kasschau KD, Carrington JC: Long-distance movement and replication maintenance functions correlate with silencing suppression activity of potyviral HC-Pro. Virology 2001, 285:71-81.

35. Bayne EH, Rakitina DV, Morozov SY, Baulcombe DC: Cell-to-cell movement of potato potexvirus $x$ is dependent on suppression of RNA silencing. Plant J 2005, 44:471-482.

36. Powers JG, Sit TL, Qu F, Morris TJ, Kim KH, Lommel SA: A versatile assay for the identification of RNA silencing suppressors based on complementation of viral movement. Mol Plant-Micro Interact 2008, 21:879-890.
doi:10.1186/1743-422X-7-335

Cite this article as: Wu et al:: Identification of Pns6, a putative movement protein of RRSV, as a silencing suppressor. Virology Journal $20107: 335$.

\section{Submit your next manuscript to BioMed Central and take full advantage of:}

- Convenient online submission

- Thorough peer review

- No space constraints or color figure charges

- Immediate publication on acceptance

- Inclusion in PubMed, CAS, Scopus and Google Scholar

- Research which is freely available for redistribution

Submit your manuscript at www.biomedcentral.com/submit
Biomed Central 